\title{
O funcionamento do Programa de Atendimento a Alunos com Altas Habilidades/Superdotação (PAAAH/SD-RJ)
}

Cristina Maria Carvalho Delou*

\section{Resumo}

Trata-se da apresentação do funcionamento do Programa de Atendimento a Alunos com Altas Habilidades/Superdotação (PAAAH/SD), realizado na Faculdade de Educação da Universidade Federal Fluminense, localizada em Niterói, regiāo metropolitana da cidade do Rio de Janeiro. O programa articula açóes de ensino, pesquisa e extensão. Os objetivos do PAAAH/SD podem ser categorizados em diagnóstico, orientação a família e a escola, Atendimento Educacional Especializado, Aceleração de Estudos, formação docente e pesquisa. O Programa é realizado com base na metodologia da pesquisa-ação, que busca soluções coletivas e individuais, a partir da identificação das demandas sociais apontadas pelas famílias de alunos com altas habilidades/superdotaçáo e alunos da UFF que procuram o programa. Os alunos diagnosticados com altas habilidades/superdotação são convidados a participarem das atividades acadêmicas de formação dos futuros professores das redes regulares de ensino, o que permite contato direto com este tipo de alunado. Os resultados podem ser vistos na demanda crescente pela busca dos serviços e na criaçáo de uma nova disciplina para os cursos de licenciatura oferecidos pela UFF. Todo o trabalho é gratuito. Nas Considerações Finais, aponta-se a interface do PAAAH/SD com o recém criado Programa Escola de Inclusão. Pela Escola de Inclusão, que oferece cursos de férias de Libras, Braille, Materiais Didáticos Acessíveis e passará a oferecer oficinas de Robótica Educativa, alunos diagnosticados com altas habilidades/superdotação e interessados nesta área realizarão protótipos eletrônicos móveis. Estes serão interpretados pelos estudantes de Matemática e Física que tirarão as equações presentes nos modelos. Estes estudos começarão no segundo semestre de 2010 e nas férias de julho de 2011, todos os envolvidos levarão aos alunos com deficiência visual do Instituto Benjamin Constant suas experiências. São novas aprendizagens que favorecerão a construção de conhecimentos formais em Robótica Educativa, Matemática e Física além da formaçáo de valores humanitários nos futuros professores da sociedade inclusiva brasileira.

Palavras-chave: Altas Habilidades/Superdotação; Enriquecimento escolar; Inclusão.

* Professora Doutora da Universidade Federal Fluminense (UFF). Niterói, Rio de Janeiro, Brasil.

Revista Educação Especial | v. 27 | n. 50 | p. 675-688 | set./dez. 2014

Santa Maria

Disponível em: <http://www.ufsm.br/revistaeducacaoespecial> 


\section{The operation of the Program to Serve High Able/ Gifted Students (PAAAH/SD-RJ)}

\section{Abstract}

This work presents the Program to Assist Students with High Abilities/Giftedness (PAAAH/SD) held at the Faculdade de Educação of the Universidade Federal Fluminense, located in the city of Niterói, part of the Metropolitan Region of the city of Rio de Janeiro. The Program articulates actions of teaching, research and extension. The objectives of PAAAH/SD can be categorized in: diagnosis, genetic counseling for families and schools, specialized educational service, acceleration in education, teacher training and research. The program is conducted on the basis of the methodology of action research. It seeks collective and individual solutions for the demands pointed either by undergraduate students or the families of students with high abilities/giftedness from the basic education. Students diagnosed with high abilities/ giftedness are invited to participate in academic activities with the undergradute students of training of future teachers for the network of regular education. The results can be seen in the increasing demand for search services and the creation of a new discipline for under graduation courses offered by UFF. All activities of the university are free. In Final Thoughts, it is shown that there is an interface between PAAAH/SD and the newly created Program School of Inclusion. The School of Inclusion offers vacation courses of Libras, Braille, Accessible Teaching Materials and plans on offering workshops on Educative Robotics, in which students diagnosed with high skills/ giftedness, or the ones interested in this area, will be able to make electronic mobile prototypes. These prototypes will be studied by mathematics and physics' undergraduate students, who will present the equations necessary to understand such models. These studies will begin in the second half of 2010 and in July 2011 vacation period. All people involved will take their experiences to students with visual impairments at the Instituto Benjamin Constant. These new lessons will facilitate the construction of formal knowledge in Educative Robotics, Mathematics and Physics beyond the acquisition of humanitarian values in the future teachers of the Brazilian inclusion society.

Keywords: High Abilities/Giftedness; School enrichment; Inclusion.

\section{Introdução}

Quando ingressei, por concurso público, para lecionar Educação Especial na Faculdade de Educação da Universidade Federal Fluminense, já trazia uma importante experiência no atendimento educacional especializado aos alunos com altas habilidades/superdotação, acumulada pela formação acadêmica, pesquisa e prestação de serviço. Uma vez docente, introduzi conteúdos específicos que passaram a ser ministrados na disciplina obrigatória Educação Especial, oferecida para o oitavo período do curso de graduação em Pedagogia, na disciplina optativa para a Pedagogia e eletiva para as licenciaturas com a denominação de Tópicos Especiais em Educação Especial 
e um curso de pós-graduação lato-sensu teve seu foco ampliado para incluir esta área de conhecimento, a fim de atender à demanda reprimida de formação de professores na região metropolitana da cidade do Estado do Rio de Janeiro.

As aulas na graduação e pós-graduação lato-sensu foram dadas, estágios foram realizados em escolas públicas do município do Rio de Janeiro, onde o atendimento era realizado desde 1974, monografias de final de curso foram realizadas, mas a questáo do diagnóstico ainda era complexa. Náo havia locais onde o diagnóstico pudesse ser feito e que oferecesse orientaçáo adequada tanto para a escola quanto para a família. A demanda pelo diagnóstico percebida desde 1992, mostrou a falta do serviço especializado oferecido de modo público ou particular. Vieram alunos de outros municípios e de todas as idades. Vieram famílias e professores. Mas, objetivamente, apenas cada aluno era beneficiado, observando-se que não havia uma extensão do benefício da identificação para demais alunos da mesma escola (DELOU, 2005).

Ciente dos objetivos da universidade pública relacionados à indissociabilidade das ações de ensino, pesquisa e extensão, decidi elaborar um projeto que oferecesse uma série de oportunidades aos alunos matriculados nas diferentes licenciaturas, articulando os objetivos da formação teórico-prática da acadêmica no contexto da pesquisa e da extensão, por intermédio dos serviços prestados à comunidade. Direta e indiretamente, tanto os alunos da universidade, quanto a comunidade, seria beneficiada com os projetos desenvolvidos.

Em 2002, foi formalizado o Projeto de Atendimento a Alunos com Altas Habilidades/Superdotaçáo (PAAAH/SD), vinculado à Faculdade de Educação e nele envolvendo alunos dos cursos de licenciatura e professores dos mais diversos cursos de graduação. Inicialmente inscrito, na Pró-Reitoria de Extensão foi caracterizado como Atividade de Integração ensino/serviço/comunidade. Inicialmente, recebeu alunas bolsistas entre os anos de 2002 e 2005, assim como alunos e alunas em fase de conclusão de curso de graduação, de pós-graduação lato-sensu e stricto-sensu (mestrado) para a realizaçáo da pesquisa empírica de seus estudos acadêmicos. Após 2005, o projeto deixou de receber bolsistas de extensão por motivos institucionais, ficando apenas com os estudantes de licenciaturas em fase final de curso e monografia.

\section{Objetivos}

Os objetivos do Programa de Atendimento a Alunos com Altas Habilidades/ Superdotação são:

a) Identificação de alunos com altas habilidades/superdotação para o trabalho especializado no ambiente escolar e diagnóstico diferencial;

b) Orientação a família e a escola;

c) Orientação para Aceleração de Estudos;

d) Atendimento Educacional Especializado em diferentes espaços de pesquisa universitária;

e) Formação teórico-prática para o exercício docente na perspectiva da educa-ção inclusiva;

f) Elaboração de trabalhos acadêmicos de pesquisa. 


\section{Metodologia}

A metodologia desenvolvida no Programa de Atendimento a Alunos com Altas Habilidades/Superdotação é a da pesquisa-ação. Realizada no seio da sociedade, suas ações formam, questionam, propõem soluçôes de problemas nascidos no coletivo onde sujeitos e pesquisadores envolvidos na situação e interessados no tema estão comprometidos entre si. (THIOLLENT, 1997).

A pesquisa-ação como método intervencionista permite ao pesquisador testar hipóteses sobre o fenômeno estudado, implementando e acessando as mudanças no cenário real, o que é bastante favorável neste momento de implementação de políticas públicas de inclusão (LINDGREN et al., 2004). A pesquisa-ação favorece que o pesquisador aplique os conhecimentos produzidos na pesquisa, o que beneficia a todos os envolvidos na educação de alunos com altas habilidades/superdotação, tão excluídos das práticas docentes.

A Entrevista Diagnóstica - a participação no Programa de Atendimento a Alunos com Altas Habilidades/Superdotação começa com a marcação de uma entrevista diagnóstica para delineamento da história de vida (GLAT, 1989; GLAT; MÜLLER, 1999) de cada sujeito a ser avaliado. Esta etapa é feita por meio de entrevista semi-estruturada (TRIVIÑOS, 2006; CHIZZOTTI, 2008) para levantamento dos dados de identificação, pessoal e familiar quanto aos aspectos idade, moradia e religião; dados de caracterização pessoal e familiar relativos à escola: nível de escolaridade, série, localização, tipo (pública ou particular), desempenho escolar e o primeiro registro sobre áreas de interesses. Levantavam-se os dados de precocidade no andar, falar, ler, escrever, interpretar, calcular, mecânica, eletrônicos e informática. Identificam-se os antecedentes familiares de altas habilidades/superdotação com ou sem atendimento especializado, buscando-se informaçôes de autodidatismo. E, por fim, o relato aberto sobre o desenvolvimento geral do sujeito avaliado relativo ao que mais chamava mais a atenção das pessoas quando menor, suas preferências e dificuldades de adaptação na vida em sociedade.

Os documentos escolares (histórico, boletins, relatórios escolares e provas) são analisados para efeitos de registro do desempenho escolar.

Nesta etapa, se segue a avaliação psicológica por meio de testes e atividades. Avaliam-se as áreas da inteligência, personalidade e criatividade sem a preocupação com a patologização dos comportamentos, mas com a descoberta dos talentos. São utilizados os testes: Matrizes Progressivas de Raven (Escalas Especial e Geral), Cubos de Kohs, HTP, Minhas Mãos, Viso-motor de Bender e atividades de expressão da criatividade. Quando necessários, outros instrumentos são utilizados de acordo com cada caso.

Em seguida, todos os formulários produzidos com as informaçóes da entrevista diagnóstica são reunidos numa pasta catálogo de modo que as informaçóes favoreçam aos estudos de casos. O tempo de duração de cada avaliação variava de acordo com cada caso. O serviço é gratuito e continua sendo o único em toda a região metropolitana. 
A Entrevista Diagnóstica também tem a finalidade de favorecer a realização do diagnóstico diferencial de altas habilidades/superdotação de outros quadros como o Transtorno de Asperger. É fato que a chamada hiperlexia induz às famílias a acharem que seus filhos são superdotados, mas é necessário atenção pelas características próprias de cada quadro.

Orientação a Família - Em seguida, a Entrevista Diagnóstica realiza-se a Orientação a Família conforme a origem da solicitação do diagnóstico e a necessidade de encaminhamentos que busquem o bem-estar do sujeito avaliado na família e na escola. A família das crianças com altas habilidades/superdotação vive desafios inerentes às suas responsabilidades para o atendimento básico das necessidades de manutençáo, sobrevivência e estimulação daqueles a quem serve de modelo para a formação, imitação e inspiração desde as primeiras relaçóes interpessoais. É na família que começa a construção da nova personalidade, com base nos parâmetros ético-morais, cultivados pelo grupo, alicerce das subjetividades em formaçáo e que os pequeninos apresentarão, quando forem atores sociais, cidadãos com direitos e deveres das sociedades a que pertencerem. (DELOU, 2007).

Nem sempre a família está segura a respeito do desenvolvimento da criança que se diferencia e necessita de orientação, ao mesmo tempo que nem sempre têm consciência de que as suas atitudes são de fundamental importância para o desenvolvimento das crianças e dos adolescentes que estáo no seu convívio. Estudos realizados após os anos 1960, avaliaram a influência dos pais e das famílias sobre jovens ou adultos que se destacaram em seu campo de conhecimento. Goertzel \& Goertzel (1962), Bloom (1985) Gross (2000) encontraram uma enorme influência dos pais sobre as altas habilidades/superdotação dos filhos. Contudo, não basta que crianças e adolescentes apresentem, espontaneamente, talentos e capacidades precoces ou que exibam notável potencialidade nas diversas áreas do aprender a conhecer, aprender a fazer, aprender a conviver ou do aprender a ser, se a família náo estiver atenta para o importante papel que ela exerce sobre o desenvolvimento dos filhos (DELOU, 2007).

Orientação a Escola - feita em menor escala, a Orientação a Escola vem crescendo na medida em que os gestores escolares e os profissionais da educação, entre eles os professores vêm tomando consciência da importância de seu papel frente ao desenvolvimento dos talentos dos alunos. Regra geral, a escola orienta para que a família faça a avaliação diagnóstica a fim de buscar solução para o problema que interfere no desempenho do aluno, contudo nem sempre a escola aceita a orientação decorrente da avaliação, principalmente quando esta indica o Enriquecimento/ Aprofundamento Escolar ou a Aceleraçấo de Estudos. Embora a escola seja parte da sociedade e esteja imersa na cultura social, ela reage à influência da sociedade sobre suas açóes. Acreditando que a Educação é o caminho para o desenvolvimento de uma sociedade mais solidária, justa e humana e que a mudança de cultura é parte da formação continuada que os profissionais da educação devem buscar é que o PAAAH/ SD investe na Orientação a Escola.

Orientação para Aceleração de Estudos - a Orientação para a Aceleração de Estudos é feita sempre que a criança ou o adolescente mostram nível de desen- 
volvimento real (VIGOTSKI, 1988) assincrônico (SILVERMAN, 2002) em relação ao que é esperado para a sua idade. Por exemplo, se uma criança de 5 anos apresenta nível de desenvolvimento real de 7 e, por isso, já sabe ler e calcular mentalmente, ela não deve ser obrigada a frequentar o Jardim III, na Educação Infantil, já que suas habilidades cognitivas são superiores e dão origem a um desenvolvimento emocional diferenciado. Isto também pode ocorrer com o pré-adolescente na chegada ao segundo segmento do Ensino Fundamental e com o adolescente ao chegar no Ensino Médio.

A aceleração de estudos é um processo escolar que foge ao padrão usual da seriação, exigindo compatibilidade com a legislação vigente. Desde 1996, o Brasil garante pela LDB a "aceleração para concluir em menor tempo o programa escolar para superdotados", (BRASIL, 1996) que pode ser realizada mediante a avaliaçáo de conhecimentos na própria escola e documentada em registros administrativos.

Quando indicada, a Aceleração de Estudos é feita no PAAAH/SD na forma de programa, uma vez que, segundo Southern \& Jones (apud. COLANGELO, 2004, pp. 25,) há 18 tipos de Aceleraçáo de Estudos e o Brasil prevê todos eles na LDB e nos documentos legais, dela, decorrentes, conforme pode ser visto em seguida:

1. Ingresso antecipado no Jardim de Infância (LDB, Art. 24, II - c)

2. Ingresso antecipado no Ensino Fundamental (LDB, Art. 24, II - c)

3. Saltar séries ou anos (LDB, Art. 24, II - c)

4. Avanço contínuo (LDB, Art. 24, V- c)

5. Ensino segundo o ritmo do estudante (LDB, Art. $4^{\circ}, \mathrm{V}$ )

6. Aceleração de matérias / Aceleração parcial (LDB, Art. 24, IV)

7. Classes combinadas (LDB, Art. 24, IV)

8. Plano de estudos compactado (LDB, Art. 23)

9. Plano de estudos abreviado (LDB, Art. 23)

10. Mentores (previsto nos Programas com orientação acadêmica como a iniciação científica, PET e todas as demais bolsas)

11. Programas extracurriculares (previsto nos Projetos Pedagógicos dos cursos de Graduação, e nas bolsas de pesquisa e extensão)

12. Cursos a distância (LDB, Art. $32, \$ 4^{\circ}$ )

13. Graduação antecipada (LDB, Art. 47, \$1º)

14. Curso simultâneo/paralelo

15. Colocação Avançada (LDB, Art. 24, IV)

16. Créditos por provas (LDB, Art. 47, $\$ 2^{\circ}$ )

17. Aceleração universitária (LDB, Art. 47, \$ 2º) 
18. Ingresso antecipado no Ensino Médio, pré-vestibular ou universidade (apenas comprovando documentação relativa aos níveis de ensino anteriores, LDB).

Além destes artigos que estão fora do Capítulo 5, que trata especificamente da Educação Especial, neste capítulo há o Art. 59 que assegura aos educandos com necessidades especiais: I - currículos, métodos, recursos educativos, e organizaçóes específicos, para atender às suas necessidades. Uma vez indicadas as características do aluno identificado com altas habilidades/superdotação e constatada a grande flexibilidade da LDB nas proposiçôes organizativas da Educação Básica encontrada nos Artigos 23 e 24, associados ao previsto nos Artigos 58 e 59, novas formas de organização escolar poderão ser realizadas.

Por isso, todo cuidado é pouco quando indica-se a Aceleração de Estudos uma vez que, segundo Colangelo (2007a, p. 18), "as decisôes sobre aceleração, tradicionalmente, têm estado baseadas em prejuízos pessoais ou informaçóes incorretas e incompletas." Sempre imaginamos que o aluno a ser acelerado irá queimar etapas do desenvolvimento sem percebermos que ele já vivenciou estas etapas de modo tão rápido que nem nos demos conta. É justamente o desconforto produzido pela assincronia que nos faz avaliar o que se passa com a adaptação escolar do aluno, buscando pela Aceleração de Estudos um lugar mais produtivo e menos entediante para o aluno com altas habilidades/superdotação.

Atendimento Educacional Especializado - estando na Universidade, o PAA/ AH/SD oferece Programa de Enriquecimento/Aprofundamento Escolar de forma Tutorial nas Unidades de Ensino de acordo com os talentos dos alunos identificados. Realizado em menor quantidade, este tipo de atendimento depende de disponibilidade pessoal dos alunos, que ainda cursam a Educaçáo Básica, para freqüentarem as aulas oferecidas junto aos alunos universitários ou individualmente e da disponibilidade de professores universitários para orientarem alunos que ainda estão na Educação Básica e que contam menor autonomia em relação aos universitários.

Já foram realizados projetos na Pedagogia (de Xadrez e no Laboratório de Informática em Educação Especial), História, Letras (Português/Latim), Antropologia, Arquivologia/Documentação, Matemática, Literatura, Física, Biologia e Vestibular Popular.

Foram contatados doze (12) professores, entre especialistas, mestres e renomados doutores, que desenvolveram projetos individuais de acordo com os interesses de cada aluno, promovendo uma nova forma de inclusão escolar.

Dentre os alunos atendidos, todos os que fizeram vestibular foram aprovados na UFF (Arquitetura, Letras: Português/Latim, Engenharia de Produção, Arquivologia/Documentação), na UFRJ (Filosofia), na UERJ (Direito) e estamos aguardando este ano um candidato ao Instituto de Física.

Nesta modalidade de atendimento, foram incluídos, ainda, os alunos indicados pelo Projeto Jovens Talentos para a Ciência, da Fundação Carlos Chagas de Amparo à Ciência do Estado do Rio de Janeiro - FAPERJ, que oferece bolsa de 
Iniciação Científica Jr. Este programa foi criado no Estado do Rio de Janeiro para o atendimento dos alunos do segundo ano do ensino médio, matriculados em escolas públicas, indicados pelos professores, por suas capacidades de aprendizagem e interesse científico.

Em 2007, recebemos a primeira aluna e já contabilizamos cinco, ao todo, realizando projetos de pesquisa com o objetivo de proporcionar oportunidade de escolha profissional por meio de um modelo de enriquecimento escolar, vivenciando formação científica, a partir da motivação pessoal, com criatividade e competência. Embora não se possa mais pensar a adolescência como em tempos atrás, algumas questôes ainda ocupam espaço comum: o Ensino Médio é a etapa na vida do adolescente que trás a angústia das mudanças em si mesma; é a etapa do crescimento físico, da conquista da independência, da afirmação do $\mathrm{Eu}$, da formação de grupos e dos interesses gregários, da instabilidade emocional e da escolha da profissão, entre outros, muitas vezes em idade precoce. Maturidade de escolha nem sempre pode ser observada entre os adolescentes e a decisão pela profissão futura envolve cultura, contexto social em que se vive, expectativas familiares, perspectivas de trabalho e de mercado, entre outras. Há, também, quem levante a possibilidade de motivaçóes conscientes e/ ou inconscientes dirigirem a escolha profissional. (ABREU FILHO apud GURGEL, 2006)

A decisão de desenvolver um projeto de pesquisa com base no "Modelo de Enriquecimento Escolar" se deu porque ele foi proposto pelo educador norte-americano Joseph Renzulli, com o objetivo de tornar a escola um lugar onde os talentos fossem identificados e desenvolvidos." (apud. CHAGAS, MAIA-PINTO PEREIRA, 2007), e porque o nome do Programa, Jovens Talentos para a Ciência, fala por si mesmo. Considerando-se as precárias condiçóes materiais de ensino em que muitas escolas se encontram, deixando de oferecer aos alunos mais pobres oportunidades de acesso ao conhecimento básico de Ensino Médio, o programa de iniciação científica criado, mais recentemente, parece ser uma chance de inclusão social para os alunos selecionados. São alunos com traços de altas habilidades/superdotação, invisíveis aos olhos dos professores presentes nas capacitaçóes que visam formar competências para a identificação de alunos com altas habili-dades/superdotação em sala de aulas.

Como afirmou Vigotski (1929, apud. DELOU \& BUENO, 2010), discutindo a questão da genialidade, "condiçóes econômicas e sociais favoráveis podem concorrer para um excelente aproveitamento dos talentos inatos." (VIGOTSKI, 1929, apud. DELOU; BUENO, 2010). Tão claras as suas palavras por não negar o que desconhecemos, ou seja o modo como se produz biologicamente a inteligência e tão complexas por afirmar que "se a hereditariedade torna possível a genialidade, somente o ambiente social concretiza esse potencial, e cria o gênio". (VIGOTSKI, 1929, apud. DELOU; BUENO, 2010) Ou seja, se os ambientes escolares não melhorarem de modo a oferecer outras condiçóes escolares aos jovens estudantes brasileiros, nós perderemos muitos cientistas, artistas, políticos entre outros profissionais por falta de acesso aos conhecimentos e oportunidades para ingressarem e permanecerem no ensino superior. 
Parcerias: Um dos papéis desempenhados pelo PAAAH/SD tem sido apoiar na forma de parceria as atividades desenvolvidas por outros núcleos e entidades não governamentais. Foi o caso do Núcleo de Atividades para Altas Habilidades/Superdotação (NA-AH/S-RJ) que, localizado próximo à UFF, iniciamos parceria técnica, ad hoc, com suas três Unidades, Professor, Aluno, e Família, para a realização açóes conjuntas em 2006, 2007 até a metade de 2008. Neste período, foram realizadas assessorias para diagnóstico, atendimento educacional, formação de professores e o grupo de estudos Diálogos Criativos, em que foram discutidos casos, legislaçôes e políticas públicas como a nova Política Nacional de Educação Especial na Perspectiva da Educação Inclusiva.

Outra parceria foi com o Instituto Rogério Steinberg, que havia começado de modo informal em 1999 e em 2010 se institucionalizou por meio de uma capacitação para os professores da Secretaria Municipal de Educação do Município do Rio de Janeiro. Esta capacitaçáo teve o objetivo de favorecer condiçóes para que os professores e especialistas em Educação desenvolvessem melhor compreensão sobre altas habilidades/superdotação.

Uma terceira parceria tem se mantida com o ISMART e a nossa finalidade é a de divulgar seus projetos.

O conjunto de experiências desenvolvidas ao longo de dezoito (18) anos consecutivos no ensino superior mostra que ainda existe demanda social pela falta de atendimento educacional especializado nas escolas públicas e privadas da regiáo. Mostra, também, que ainda existem mitos (ALENCAR; FLEITH 2001, WINNER, 1998) a serem vencidos. Contudo, aparentemente, parece que as açóes ganharam força política com a nova Resoluçáo CNE/CEB No 04 de 2009, que Institui Diretrizes Operacionais para o Atendimento Educacional Especializado na Educação Básica, modalidade Educação Especial. Esta Resoluçáo prevê, no Artigo 5ª que o Atendimento Educacional Especializado

é realizado, prioritariamente, na sala de recursos multifuncionais da própria escola ou em outra escola de ensino regular, no turno inverso da escolarização, não sen-do substitutivo às classes comuns, podendo ser realizado, também, em centro de Atendimento Educacional Especializado da rede pública ou de instituiçôes comuni-tárias, confessionais ou filantrópicas sem fins lucrativos, conveniadas com a Se-cretaria de Educação ou órgão equivalente dos Estados, Distrito Federal ou dos Municípios. (BRASIL, 2009)

Isso representa um avanço no que diz respeito às parcerias que podem ser realizadas pelos sistemas de ensino que ainda náo institucionalizaram o atendimento educacional especializado para alunos com altas habilidades/superdotaçâo. Estas parcerias poderão ser feitas com as entidades não-governamentais que vêm realizando tais projetos. 
Além disso, há ainda o Artigo $7^{\circ}$ que diz que

Os alunos com altas habilidades/superdotação terão suas atividades de enrique-cimento curricular desenvolvidas no âmbito de escolas públicas de ensino regular em interface com os núcleos de atividades para altas habilidades/superdotação e com as instituições de ensino superior e institutos voltados ao desenvolvimento e promoção da pesquisa, das artes e dos esportes. (BRASIL, 2009)

Ou seja, nós das universidades podemos, efetivamente, receber os alunos com altas habilidades/superdotação para favorecer-lhes o acesso aos níveis mais elevados de ensino.

Formação teórico-prática para o exercício docente na perspectiva da educaçáo inclusiva: com as novas açôes relativas às políticas de inclusão na universidade, o PA-AAH/SD passou a integrar a Núcleo de Acessibilidade e Inclusão - Sensibiliza UFF, desde 2006. Neste sentido temos participado das atividades coletivas como o Acolhimento Estudantil dos novos calouros, fazendo a recepção dos nossos próprios alunos aprovados na UFF.

Participamos da realização dos Seminários sobre Inclusão de Pessoas com Necessidades Especiais no Ensino Superior na UFF (2007, 2008 e 2009) e temos podido constatar o brilhantismo e os talentos dos alunos com deficiências que realizam nossos cursos de graduação e bacharelado. Temos registrado dois alunos cegos (um rapaz que faz História e uma moça que faz Psicologia), uma aluna surda que faz Química Industrial, um aluno com tetraplegia e comprometimento psicomotor generalizado (mãos e fala) que se formou em Física com Coeficiente de Rendimento acima de 9,5 (nove e meio). Agora, ele realiza o curso de mestrado em Física com área de pesquisa em radiação em cavernas e seu destaque acadêmico é digno de registro.

O projeto mais recente e que nos instiga para a inovação é a interface do Programa de Atendimento a Alunos com Altas Habilidades/Superdotação com o recém criado Programa Escola de Inclusão. Contemplado com o PROEXT/MEC-2009 e o PROEXT/MEC-2010, este programa de extensão universitária tem o objetivo geral de formar professores de diferentes áreas do conhecimento (Ciências Biológicas, Ciências Sociais, Educação Física, Enfermagem, Filosofia, Física, Geografia, História, Letras/Alemão, Espanhol, Francês, Grego, Inglês, Latim, Italiano, Literaturas, Matemática, Pedagogia, Psicologia e Química), em Libras, Braille e Materiais Didáticos Acessíveis.

Na Escola de Inclusão, aprovada em 2009, destacam-se os comportamentos observados no alunado que faz parte da equipe de apoio, constituída de alunos que criaram e lecionam sobre Materiais Didáticos Acessíveis durante os cursos realizados nas de férias de julho (2009 e 2010) e em outubro (2009), durante a Agenda Acadêmica da UFF. Tais alunos mostraram os comportamentos descritos por Renzulli (1978, 1994, 1985), na Teoria dos Três Anéis, ou seja, habilidades acima da média, criatividade e grande envolvimento com as tarefas. Todos os Materiais Didáticos Acessíveis criados já foram testados com alunos cegos e surdos da Educação Básica e 
mostraram forte potencialidade para a transmissão de conceitos científicos representados por imagens e palavras, regra geral, inacessíveis aos alunos cegos e surdos.

Um estudo mais aprofundado está sendo realizado com vistas a identificar os indicadores de altas habilidades/superdotação dos alunos que constituem a equipe de apoio da Escola de Inclusão, sem que nunca tenham tido qualquer tipo de atendimento educacional especializado para o desenvolvimento de suas altas habilidades/ superdotação.

Na Escola de Inclusão, aprovada pelo MEC para 2010/2011, destaca-se outro caráter inovador do Programa de Atendimento a Alunos com Altas Habilidades/Superdotação e que terá início neste segundo semestre de 2010, durante a oferta da disciplina Práticas Educacionais para Alunos com Altas Habilidades/Superdotação. Esta disciplina de 60 horas, divididas em 30 horas teóricas e 30 horas práticas, oferecida para alunos dos cursos de Pedagogia e demais licenciaturas, oferece oportunidade de práticas pedagógicas com alunos com altas habilidades/superdotação diagnosticados gratuitamente pelo PAAAH/SD.

Os alunos diagnosticados com altas habilidades/superdotação participarão de grupos de Atendimento Educacional Especializado formados por cinco licenciandos e um ou mais alunos com altas habilidades/superdotação uma vez por semana, durante o período de duas horas relativas às horas de prática da disciplina. Cada grupo desenvolverá atividades pedagógicas voltadas para os interesses ou habilidades dos alunos com altas habilidades/superdotação. Estão previstos atendimentos em áreas acadêmicas diversas: Física, Matemática, Geografia, Comunicação e Filosofia.

Temos duas grandes expectativas: uma com as atividades de Artes Plásticas, pois a aluna diagnosticada com altas habilidades/superdotação é surda, usuária de Libras, o que pensamos ajudará a disseminar esta língua entre todos do grupo. A segunda expectativa diz respeito aos projetos de Robótica Educativa a serem desenvolvidos com os alunos já diagnosticados com altas habilidades/superdotação e os alunos dos cursos de Matemática e/ou Física. A metodologia, sempre de pesquisa-ação, oferecerá oportunidades para que alunos com altas habilidades/superdotação façam protótipos com movimentos eletrônicos, enquanto os futuros professores de Matemática e/ou Física identificarão as equaçôes implícitas em cada projeto. Os alunos da UFF trabalharão pedagogicamente com os alunos com altas habilidades/superdotação sobre estas equaçóes. Em 2011, quando todos estiverem seguros dos novos conhecimentos adquiridos, todos irão ao Instituto Benjamin Constant e desenvolverão uma oficina pedagógica com os alunos cegos do Ensino Fundamental para repasse das novas aprendizagens testando a metodologia de ensino que inclui a participação de alunos com altas habilidades/superdotação, autores dos protótipos.

Nosso objetivo com esta nova atividade é o de formação de futuros professores, oriundos dos cursos de licenciaturas e dos grupos de alunos diagnosticados com altas habilidades/superdotação, diferenciados por valores humanitários focados na sociedade inclusiva. $\mathrm{O}$ bom uso da inteligência a serviço do bem na sociedade brasileria. 
Elaboraçáo de trabalhos acadêmicos de pesquisa - a culminância da formação inicial dos estudantes da UFF é o trabalho de final de curso. O PAAAH/SD continua apoiando os alunos de graduação e pós-graduação que desejam estudar o assunto, favorecendo o acesso aos alunos com este perfil definido e criando ambientes de aprendizagem onde estudos e pesquisas possam se desenvolver. Enquanto um maior número de cursos de formação stricto-sensu não forem criados com vistas à formação de docentes do ensi-no superior e de pesquisadores para a área das altas habilidades/superdotação continua-remos encontrando dificuldades no atendimento educacional especializado destes alunos, preferencialmente na rede regular de ensino, nas salas de aulas regulares, ou mesmo nas salas de aulas multifuncionais. Sem professores qualificados não há como identificar ou atender alunos com altas habilidades/ superdotaçáo nas escolas das redes públicas e privadas de ensino.o

\section{Considerações finais}

O Funcionamento do Programa de Atendimento a Alunos com Altas Habilidades/Superdotaçáo (PAAAH/SD-RJ) tem propiciado aos alunos da UFF oportunidades diferentes de formação profissional para a docência. Contudo, não basta e não é suficiente. Ainda falta a consolidação de cursos de pós-graduação stricto-sensu, mestrado e doutorado profissional e acadêmico, com vistas a formação de professores voltados para as práticas pedagógicas realizadas na escola e para a formação de docentes de ensino superior e de pesquisadores que atuem com objetos de pesquisa relacionados às altas habilidades/superdotação.

Não tenho dúvida da importância da formação de professores críticos e reflexivos, mas sinto que não basta. A escola demanda profissionais aptos, talentosos, comprometidos e que estejam ou sejam estimulados a criar, inovar sem medo ou preconceito em relação aos resultados. Assim, como faltam professores qualificados para o trabalho com alunos com altas habilidades/superdotação.

Nossa cultura escolar está cristalizada em saberes e fazeres que não atendem mais à realidade do aluno novo, do aluno de cérebro e fazer tecnológico, do aluno que mesmo oriundo das classes populares já possui experiências com as redes sociais na Internet, Blogger, Facebook, Flickr, Google, Myspace, MSN, Orkut, Twitter, Youtube, Wikipidia, entre outros.

É preciso avançar e enfrentar a realidade da sociedade digital, impulsionada por mentes brilhantes, autodidatas, muitas vezes donos de valores humanitários surpreendentes e que a nossa escola desconhece. É preciso avançar para que sejamos também criadores de tecnologia e não apenas consumidores contumazes.

O Brasil, tem um povo brilhante que é capaz de superar adversidades, contradiçóes, mas que não tem conseguido superar sozinho as dificuldades que a falta de escola com qualidade faz. Assim, vamos fazer a nossa parte e onde houver uma universidade pública e um especialista em altas habilidades/superdotação, vamos trabalhar para que as crianças e os jovens mais brilhantes possam ter acesso aos níveis superiores do conhecimento, das ciências e das artes, contribuindo para a formação de um povo bom, fraterno e justo. 
As agências de fomento têm programas de incentivo ao desenvolvimento de vocaçóes e talentos para a ciência e a inovação nas universidades, mas ainda falta a Educação Básica se empoderar deste conhecimento de forma a participar, de maneira mais efetiva, para a formação e desenvolvimento das vocaçóes e talentos dos alunos brasileiros.

\section{Referências}

ALENCAR, E. S; FLEITH, D. Superdotados: Determinantes, Educação e Ajustamento. São Paulo: EPU, 2001.

ABREU FILHO, A. G. Escolha Profissional: consciente e/ou inconsciente (122 p.). São Paulo: Vetor, 2006.

BLOOM, B. S. (Ed). Developing talent in young people. NY: Ballantine, 1985.

BRASIL. CONSELHO NACIONAL DE EDUCAÇÃO. Lei de Diretrizes e Bases da Educaçáo Nacional. Lei 9394, 1996. Disponível no site <http://www.mec.gov.br/seed/tvescola/ftp/leis/lein9394.doc>. Acesso em: 31 jul. 2010.

BRASIL. CONSELHO NACIONAL DE EDUCAÇĀO/CÂMARA DE EDUCAÇÃO BÁSICA. Resoluçáo N.o 04/2009. Disponível no site <http://portal.mec.gov.br/index.php?option=com_docman\&task=doc download\&gid=2135\&Itemid=>. Acesso em: 31 jul. 2010.

CHAGAS, J. F.; MAIA-PINTO, R. R.; PEREIRA, V. L. P. Modelo de Enriquecimento Escolar. In: FLEITH, D. $S$. (Org). A construçáo de práticas educacionais para alunos com altas habilidades/superdotaçáo: Volume 2: Ati-vidades de Estimulação de Alunos. Brasília: Ministério da Educação, Secretaria de Educação Especial, 2007.

CHIZZOTTI, A. Pesquisa em ciências humanas e sociais. São Paulo: Cortez 2008.

COLANGELO, N. Una nación engañada, V. I, 2004. Disponível no site <http://www.accelerationinstitute. org/nation_deceived/International/ND_v1_es.pdf>. Acesso em: 31 jul. 2010.

COLANGElO, N. A Nation Deceived: How Schools Hold Back America’s Brightest Students, V. II, 2004. Disponível no site <http://www.accelerationinstitute.org/nation_deceived/ND_v2.pdf>. Acesso em: 31 jul. 2010.

DELOU, C. M. C. Questóes sociais e emocionais na superdotação/dificuldades e ajustamento escolar/família e escola: perspectivas na educaçáo de alunos superdotados. In: Desenvolvendo competências para o atendimento às necessidades educacionais de alunos com altas habilidades/superdotaçáo. Coordenaçáo Geral SE-ESP/MEC. Organização Maria Salete Fábio Aranha. Brasília: Ministério da Educação, Secretaria de Educaçáo Especial, 2005.

DELOU, C. M. C. Educação dos alunos com altas habilidades/superdotação: legislaçấo e políticas educacionais para a inclusão. In: FLEITH, D. (Org.). A construçáo de práticas educacionais: Orientação a Professores. V.2. Brasília: Ministério da Educaçấo/Secretaria de Educaçấo Especial, 2007.

DELOU, C. M. C.; BUENO, J. G. S. A Genialidade, Segundo Vigotski. Revista de Educaçáo Pública. Disponível no site <http://www.educacaopublica.rj.gov.br/biblioteca/educacao/0259.html>. Aceso em: 31 jul. 2010.

GROSS, M. U. M. Issues in the Cognitive Development of Exceptionally and Profoundly Gifted Individuals. In International Handbook of Giftedness and Talent, ed. K. A. Heller, F. J. Monks, R. J. Sternberg, and R. F. Subotnik. Oxford, UK: Pergamon Press, 2000.

GLAT, R. Somos iguais a você: depoimento de mulheres com deficiência mental. Rio de Janeiro: Agir, 1989.

GLAT, R.; MÜLLER, T. M. P. Uma professora muito especial. Questóes Atuais em Educação, Vol IV, Rio de Janeiro: Sette Letras, 1999.

GOERTZEL, V.; GOERTZEL, M. G. Cradles of eminence. Boston: Little, Brown, 1962.

LINDGREN, R.; HENFRIDSSON, O.; SCHULTZE, U. Design Principles for Competence Management Systems: a Synthesis of an Action Research Study. MIS Quarterly, v. 28, n. 3, set. 2004.

RENZULLI, J. S. O que faz Superdotação? Reexaminar uma definição. Phi Delta Kappan, 60 (3), 180-184, 261, 1978. 
RENZULLI, J. S. Escolas para o desenvolvimento de talentos: um plano prático para a melhoria da escola total. Mansfield Center, CT: Creative Learning Press, 1994.

RENZULLI, J. S.; REIS, S. M. O modelo de enriquecimento schoolwide: Um plano global para a excelência educacional. Mansfield Center, CT: Creative Learning Press, 1985.

SILVERMAN, L. K. Asynchronous development. In M. NEIHART, S. M. REIS, N. M. ROBINSON; S. M. MOON (Eds.). The social and emotional development of gifted children (p. 31-40). Waco: Pufrock. 2002.

SOUTHERN, W. T.; JONES, E. D. Tipos de aceleración: dimensiones y cuestiones. In: COLANGELO, N. A Nation Deceived: How Schools Hold Back America's Brightest Students, V. II, 2004. Disponível no site <http://www.accelerationinstitute.org/nation_deceived/ND_v2.pdf>. Acesso em: 31 jul. 2010.

THIOllent, M. Pesquisa-Ação nas Organizaçóes. São Paulo: Atlas, 1997.

TRIVIÑOS, A.N.S. Introduçáo à pesquisa em ciências sociais. 1. ed., 14 reimp. São Paulo: Atlas, 2006.

VYGOTSKY, L. S. et al. Linguagem, Desenvolvimento e Aprendizagem. São Paulo: Ícone/Edusp, 1988

WINNER, H. Crianças superdotadas: mitos e realidade. Porto Alegre, Artmed, 1998.

\section{Correspondência}

Cristina Maria Carvalho Delou - Universidade Federal Fluminense, Faculdade de Educaçáo.

Rua Professor Marcos Valdemar Freitas Reis, Bloco D, sala 428, São Domingos, CEP: 24210-201 - Niteroi, Rio de Janeiro - Brasil.

E-mail: cristinadelou@globo.com

Recebido em 10 de março de 2014

Aprovado em 11 de junho de 2014 